\title{
Study of the liquefaction phenomenon due to an earthquake: case study of Urayasu city
}

\author{
S. Kamao ${ }^{1}$, M. Takezawa ${ }^{1}$, K. Yamada ${ }^{1}$, S. Jinno ${ }^{1}$, \\ T. Shinoda ${ }^{1}$ \& E. Fukazawa ${ }^{2}$ \\ ${ }^{I}$ Department of Civil Engineering, Nihon University, Japan \\ ${ }^{2}$ Environmental Control Center Co., Ltd., Japan
}

\begin{abstract}
Soil liquefaction describes a phenomenon whereby a saturated soil substantially loses strength and stiffness in response to an applied stress, usually earthquake shaking or another sudden change in stress condition, causing it to behave like a liquid. The liquefaction phenomenon due to the Great East Japan Earthquake 2011 occurred to the reclaimed land around the Tokyo Bay area. Urayasu city was caused extensive damage by liquefaction due to the earthquake, and recovery from the disaster is still going on.

This paper describes some remarkable damage against the structures due to the liquefaction by the earthquake, and indicates the possibility of liquefaction by current determination methods using published soil profile and $\mathrm{N}$ value of SPT (Standard Penetration Test). The authors also carried out a series of laboratory liquefaction tests (the cyclic undrained triaxial test) in order to make clear the characteristics of liquefaction, using Urayasu sand taken from the liquefied site in Urayasu city.

Keywords: earthquake, liquefaction, Urayasu city, damage types, liquefaction strength.
\end{abstract}

\section{Overview of the great East Japan earthquake}

The Great East Japan Earthquake ( $\mathrm{Mw}=9.0)$ occurred on Mar 11, 2011 with an epicentre about $130 \mathrm{~km}$ away from the coast of Tohoku. Figure 1 indicates the seismic intensity observed in various parts of Japan, and it shows that the earthquake was observed in a wide area of Japan. Extensive damage was caused by the huge tsunami that exceeded $10 \mathrm{~m}$ by the earthquake that occurred in the 


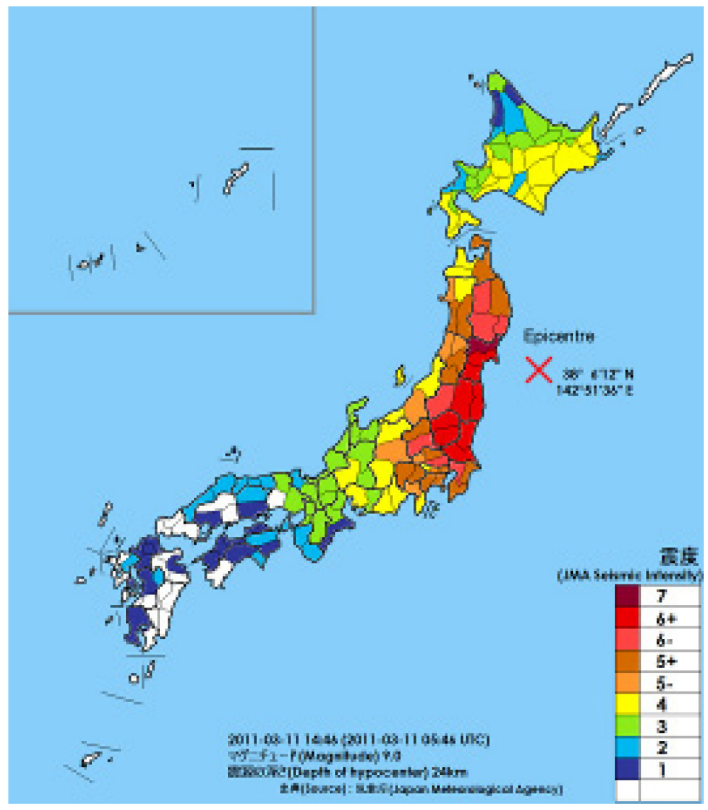

Figure 1: $\quad$ Epicentre and seismic intensity [1].

north-eastern coastal areas near the epicentre. The number of dead or missing to date (March 2013) has been more than 18,500 people.

Conversely, in the region of the coast of Tokyo Bay in the Kanto area, more than $400 \mathrm{~km}$ away from the epicentre, which has rarely seen damage caused by a tsunami, liquefaction of the ground, settlement and tilting of buildings/ground has frequently occurred.

From Figures 2 and 3, it can be seen that the liquefaction damage in the Kanto area is not only around the Tokyo Bay coast, but also the coastal areas with reclaimed soft ground in Tone River, Arakawa River and Kasumigaura which used to be a river, pond or sea. The highest amount of liquefaction damage occurred in Urayasu city where about 8,700 houses were damaged.

Figure 4(a) shows the acceleration-time history of the Great East Japan Earthquake observed in Urayasu city near the city office. The seismic wave was about 150 gal at maximum acceleration and not so large, but the duration of seismic waves was more than 70 seconds and long compared to previous earthquakes. Urayasu city is located facing Tokyo Bay, and about $75 \%$ of the land of the city was reclaimed after the 1960s, and the reclaimed area was devastated largely by the earthquake. For the comparison, Figure 4(b) shows an acceleration-time history observed at the time of the Great Hanshin-Awaji earthquake in Kobe city in 1995. The seismic wave's characteristic of the Great Hanshin-Awaji earthquake is that acceleration exceeding 400gal for about 20 seconds, and it is relatively short. Liquefaction at the Great Hanshin-Awaji earthquake was limited in the area with more than seismic intensity 6 , but in Urayasu city during the Great East Japan earthquake there was a seismic 
intensity of 5+. Therefore, long seismic wave duration is considered to be contributing to the occurrence of liquefaction. In addition, the three aftershocks $(\mathrm{Mw}=7.0,7.4,7.2)$ after the main earthquake occurred without much time difference (approximately 20 to 35 minutes) and it might also have contributed to the liquefaction.

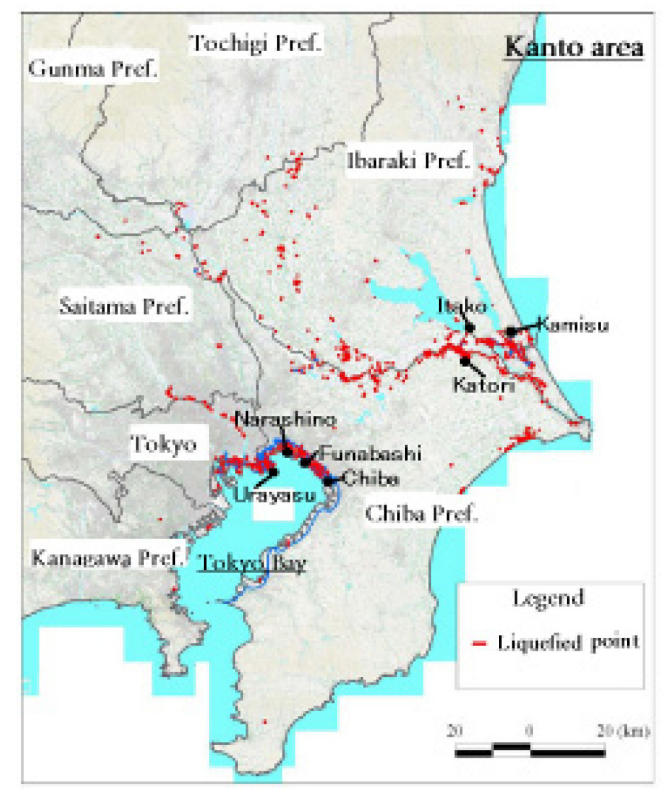

Figure 2: $\quad$ Liquefied point in the Kanto area [2].

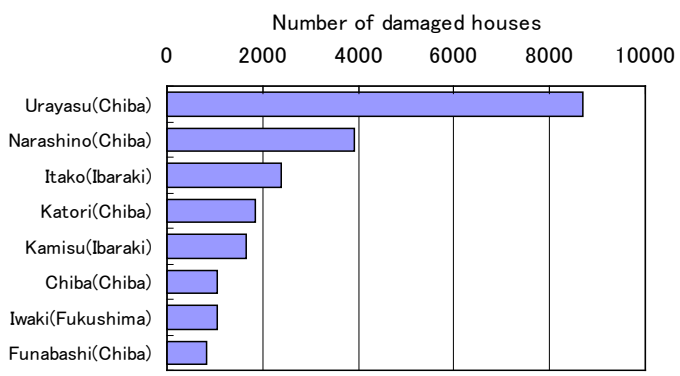

Figure 3: Number of damaged houses caused by liquefaction [2]. 

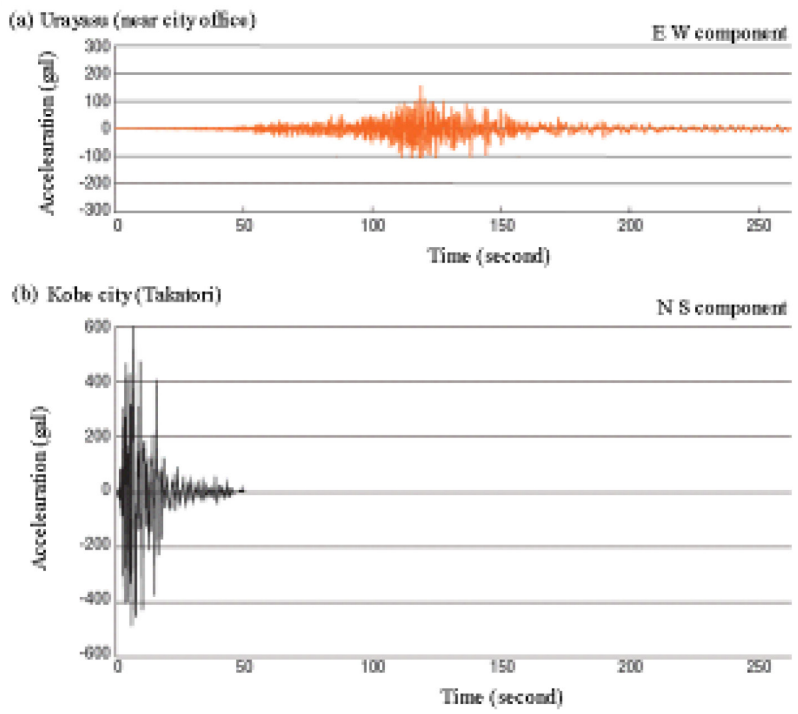

Figure 4: Observed acceleration time histories [3]: (a) The Great East Japan earthquake (2011); (b) The Great Hanshin-Awaji earthquake (1995).

\section{Characteristics of liquefaction damage in Urayasu city}

Liquefaction damage that occurred in Urayasu city occurred throughout nearly all the Nakamachi area reclaimed after 1964 and all the Shinmachi area reclaimed after 1972. A summary of the most notable damage is as follows.

(1) Damage to small residences

The ground which lost its bearing capacity by liquefaction could not support structures, and caused settlement and tilting of small residences based on spread foundation. Also, by boiling effect, sand eruptions were found in many places (Figures 5(a) and (b)).

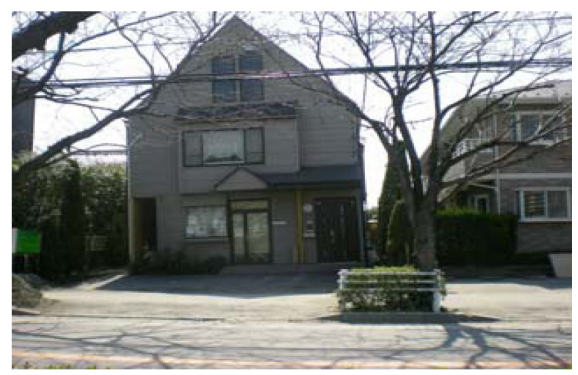

(a)

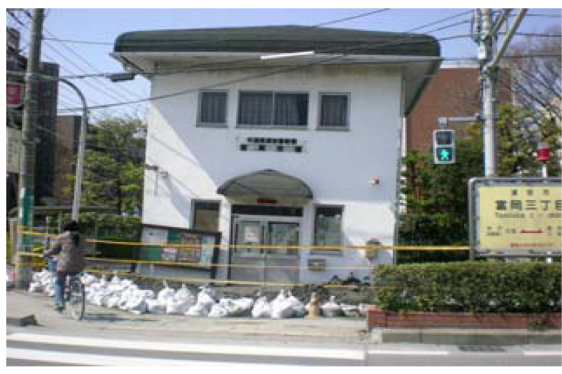

(b)

Figure 5: (a) Tilting of a small residence. (b) Tilting of a police station. 
(2) Damage to medium and large-scale buildings

Collective housing and large-scale buildings adopted a pile foundation around this area, so the damage was, relatively, not seen. However, at the contact point of the foundations and ground, there was frequent damage relating to lifelines such as drain pipes shutting off (Figure 6(a) and (b))/

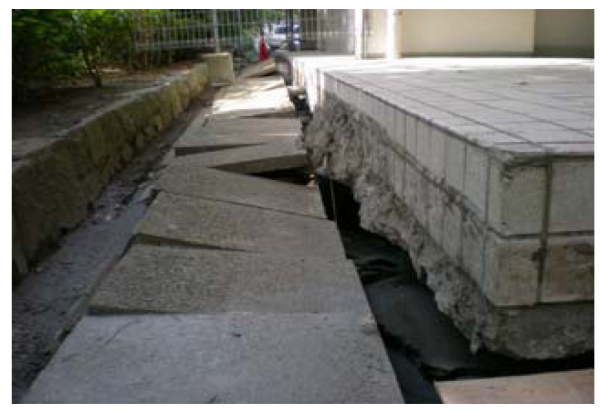

(a)

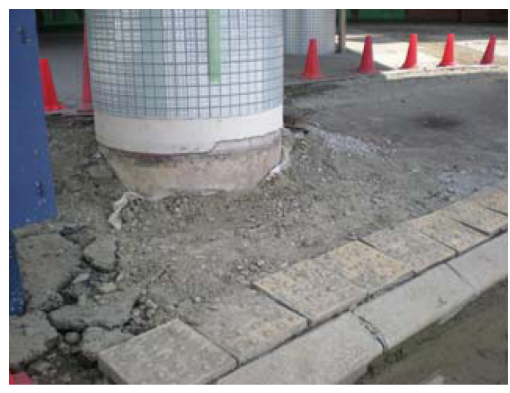

(b)

Figure 6: (a) Contact point of foundation and ground. (b) Contact point of footing and ground.

(3) Damage to other infrastructures (road and lifeline)

In the road, a sand boiling effect was seen all over from cracks in the pavement. In addition, a manhole, once lying underground was lifted by buoyancy and caused damage (Figure 7(a) and (b)).

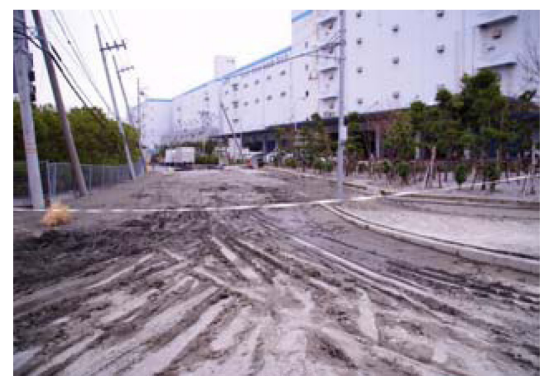

(a)

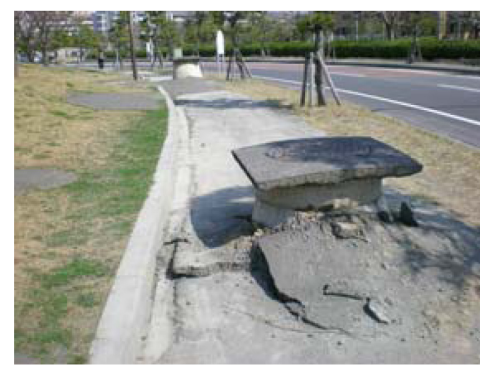

(b)

Figure 7: (a) Boiled sand on the road. (b) Lifted manhole.

\section{Overview of the terrain in Urayasu city (from past to current)}

Urayasu city, in the Chiba prefecture, faces Tokyo Bay; Edogawa River flows on the west side of the city; it also connects with the Edogawa Ward of Tokyo. It is also on the Edogawa River Delta, and was a former fishing village (see Figure 8). 


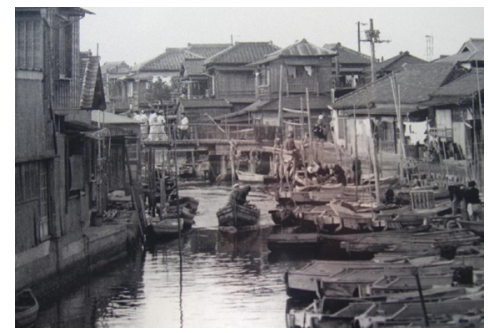

Figure 8: $\quad$ Former fishing village Urayasu in 1960s [4].

After 1964, for the purpose of creating housing, an amusement park and a distribution base for the steel industry, landfill started. At the end of 1980, with completion of the landfill, the city area had expanded 4 times more than before.

Figures 9-12 [4] are aerial photographs that show the status of the landfill in Urayasu from 1948 to the current time. As a result of reclamation, these photographs show how the city area has expanded to four times its original size.

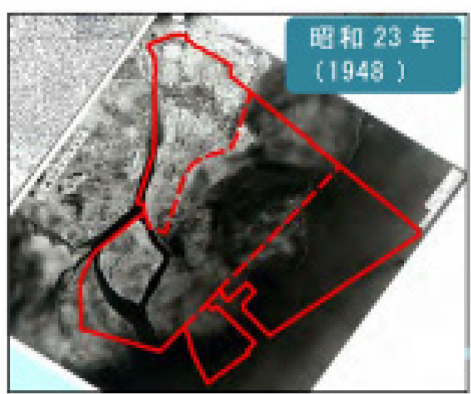

Figure 9: $\quad$ Urayasu in 1948.

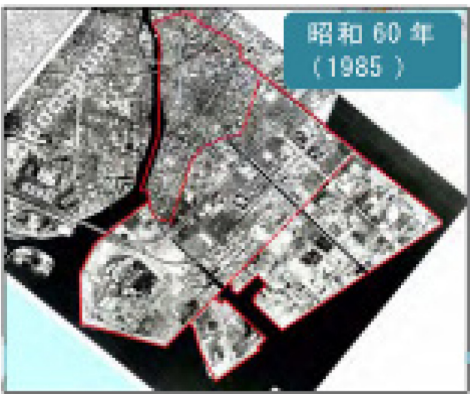

Figure 11: Urayasu in 1985.

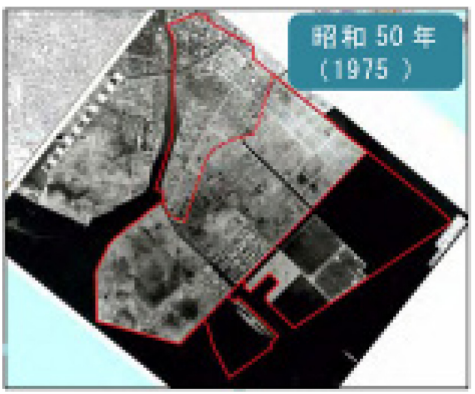

Figure 10: Urayasu in 1975.

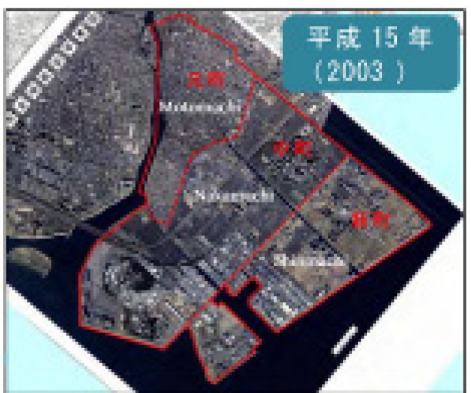

Figure 12: Urayasu in 2003.

The land in Urayasu city can be divided into 3 parts; Motomachi, Nakamachi and Shinmachi which means, respectively, Old Town, Middle Town and New Town in Japanese. Motomachi is inside the blue line in Figure 13, and is the 
Edogawa River Delta made by river deposit; it is an old town which previously flourished as a fishing village. Nakamachi is inside the yellow line in Figure 13, and reclamation started from 1964. Newest Shinmachi is inside the red line, and its reclamation took place between 1972 and 1980; this is the newest land.

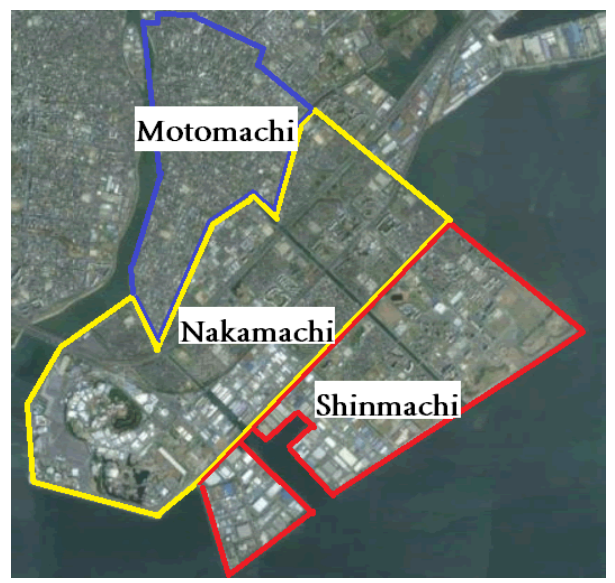

Figure 13: Three part sof Urayasu city (blue, yellow and red).

\section{Liquefaction determination method}

There are several liquefaction determination methods in Japan; in this paper the FL method and PL method are considered.

(1) FL method

Foundation design in Japan, the liquefaction was evaluated using a factor of liquefaction resistance (FL value), shown in Eq. (1) by the Japan Road Association [5]. The FL method calculates the FL value by each $1 \mathrm{~m}$, and evaluates the possibility of liquefaction quantitatively. If the FL values obtained by each depth are lower than 1.0, its land is evaluated as due to become liquefaction

$$
\mathrm{FL}=\mathrm{R} / \mathrm{L}
$$

where

FL: Liquefaction resistance factor

$\mathrm{R}$ : Dynamic shear ratio, $\mathrm{R}=\mathrm{c}_{\mathrm{w}} \mathrm{R}_{\mathrm{L}}$

$\mathrm{L}$ : Seismic shear stress ratio

$\mathrm{R}_{\mathrm{L}}$ : Cyclic triaxial shear stress ratio (20 cycles)

$\mathrm{c}_{\mathrm{W}}$ : Modification factor for earthquake ground motion

(2) PL method

As an index for the assessment of liquefaction potential, the liquefaction index (PL value) is adopted in earthquake damage assessment of many local governments in Japan by making a hazard map for liquefaction, etc. The PL 
method [6] is an evaluation method using the previous FL method with a depth of possible liquefaction and non-liquefaction layers' thickness, etc. The PL value can be obtained by following Eq. (2). Also, by using the PL value, determination of liquefaction possibility is shown in Table 1.

$$
P L=\int_{0}^{20} F * w(z) d z
$$

where $F=1-F L$ for $F L \leq 1.0$, and $F=0$ for $F L>1.0 \quad w(z)$ : a weight function to the depth, given by $w(z)=10-0.5^{*} z$.

Table 1: $\quad$ PL value and possibility of liquefaction.

\begin{tabular}{|c|c|}
\hline PL value & Liquefaction Possibility \\
\hline 0 & quite low \\
$0-5$ & low \\
$5-15$ & high \\
$15-$ & very high \\
\hline
\end{tabular}

\section{Determination of soil liquefaction in Urayasu city}

Figures 14-16 show the calculated FL value of three sites (Shinmachi, Nakamachi and Motomachi) in Urayasu city by using published boring data [7]. These figures show the data at Hinode in the Shinmachi area, at Mihama in the Nakamachi area and at Kitasakae in the Motomachi area, respectively. The PL values of these sites are shown in Table 2 by Eq. (2). From these figures and table, the calculated FL values are lower than 1.0 at any depth in the Hinode and Mihama areas which are the new reclamation lands of Shinmachi and Nakamachi. At the former fishing village of Kitasakae in Motomachi, some FL values are higher than 1.0, or the ground consists of silt deposit so that analysis of the liquefaction is not necessary. While the possibilities of liquefaction at Hinode and Mihama are "very high" because the PL values are higher than 15, at Kitasakae in Motomachi, the PL value is lower than 15, and the liquefaction possibility is "high" by Table 2 .

Table 2: $\quad$ Calculated PL value.

\begin{tabular}{|c|c|}
\hline Site & PL value \\
\hline Hinode (Shinmachi) & 31.3 \\
Mihama (Nakamachi) & 31.3 \\
Kitaei (Motomachi) & 12.4 \\
\hline
\end{tabular}

Figure 17 shows the liquefaction hazard map published by Chiba Prefecture [6]. Accuracy of this hazard map is not very high, but it indicates that the possibility of liquefaction is high in almost all areas of Urayasu city. As a subject 

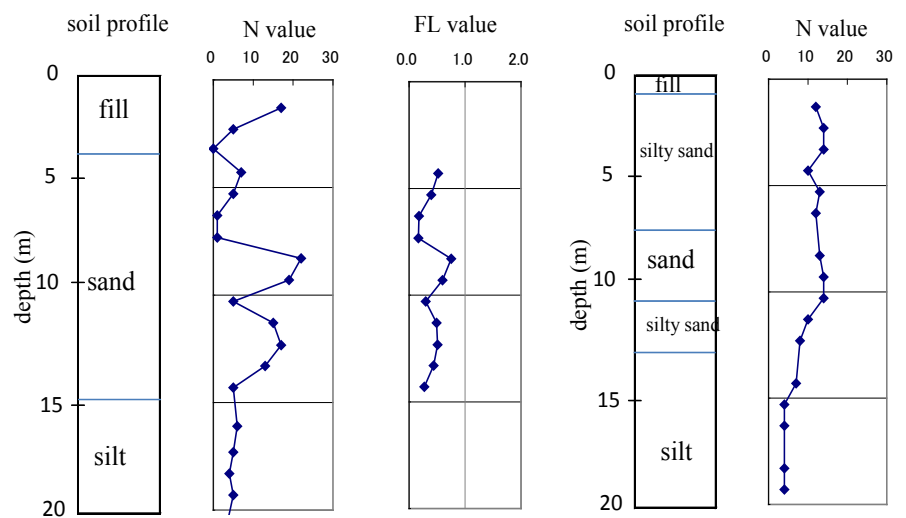

FL value

Figure 14: Calculated FL value - Figure 15: Hinode (Shinmachi).
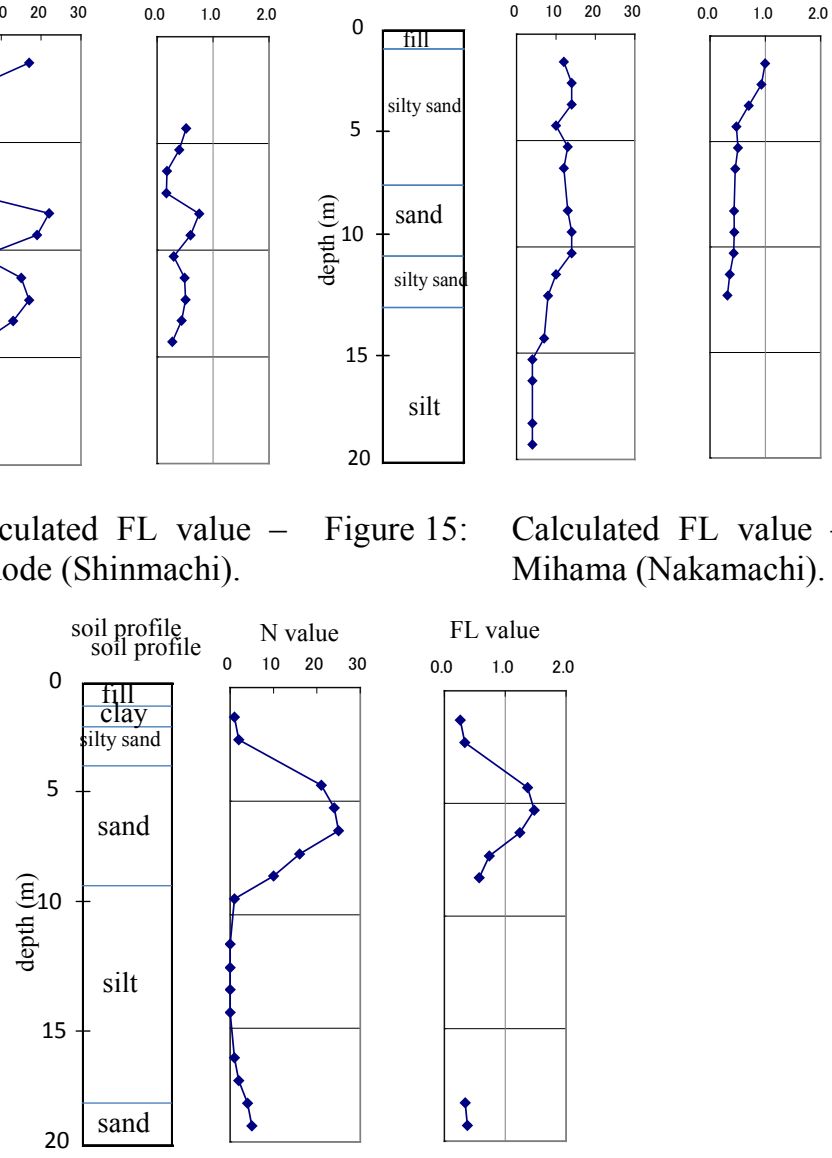

Figure 16: Calculated FL value - Kitasakae (Motomachi).

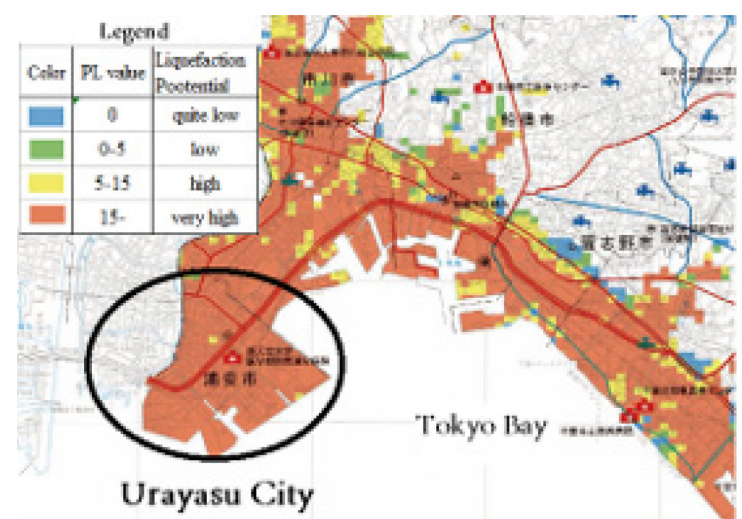

Figure 17: Liquefaction hazard map around the Tokyo Bay area [6]. 
for future discussion in liquefaction determination, it is considered to be necessary to make a highly accurate hazard map. Hazard map creation is desired by collecting existing boring data and by conducting a lot of new borings with high accuracy.

\section{Liquefaction strength of Urayasu city's sand}

By using sand samples taken from Urayasu city where the liquefaction was high in the Great East Japan earthquake, a series of cyclic undrained triaxial tests were carried out. Also, the test was taken for Toyoura standard sand for comparison purposes.

Soil profiles and test conditions are shown in Tables 3 and 4 and Figure 18, respectively. The difference between Urayasu sand and Toyoura sand is that Urayasu sand has finer grains, and the value of fine grain content is higher than Toyoura sand. Therefore, Urayasu sand's maximum density and minimum density are smaller compared to Toyoura sand.

Table 3: $\quad$ Soil properties of used

Table 4: $\quad$ Test conditions. sand.

\begin{tabular}{|c|ll|c|c|}
\hline \multicolumn{3}{|c|}{ soil properties } & Urayasu & Toyoura \\
\hline density of soil particle & $\rho_{\mathrm{s}}$ & $\mathrm{g} / \mathrm{cm}^{3}$ & 2.695 & 2.641 \\
\hline maximum density & $\rho_{\mathrm{dmax}}$ & $\mathrm{g} / \mathrm{cm}^{3}$ & 1.337 & 1.672 \\
\hline minimum density & $\rho_{\mathrm{dmin}}$ & $\mathrm{g} / \mathrm{cm}^{3}$ & 0.978 & 1.374 \\
\hline mean particle size & $\mathrm{D}_{50}$ & $\mathrm{~mm}$ & 0.148 & 0.161 \\
\hline fine fraction content & $\mathrm{F}_{\mathrm{C}}$ & $\%$ & 15.5 & 0.2 \\
\hline
\end{tabular}

\begin{tabular}{|c|c|c|c|c|}
\hline Sample & $\begin{array}{c}\text { Dr } \\
(\%) \\
\end{array}$ & $\begin{array}{c}\sigma_{\mathrm{c}}{ }^{\prime} \\
(\mathrm{kPa})\end{array}$ & $\begin{array}{c}\mathrm{f} \\
(\mathrm{Hz}) \\
\end{array}$ & $\begin{array}{c}\mathrm{R} \\
\sigma_{\mathrm{d}} /\left(2 \sigma_{\mathrm{c}}^{\prime}\right)\end{array}$ \\
\hline \multirow{3}{*}{ Toyoua } & 40 & \multirow{5}{*}{100} & \multirow{5}{*}{0.2} & $0.12,0.14,0.16$ \\
\hline & 60 & & & $0.17,0.19,0.21$ \\
\hline & 80 & & & $0.21,0.24,0.29$ \\
\hline \multirow{2}{*}{ Urayasu } & 60 & & & $0.17,0.19,0.21$ \\
\hline & 80 & & & $0.21,0.24,0.29$ \\
\hline
\end{tabular}

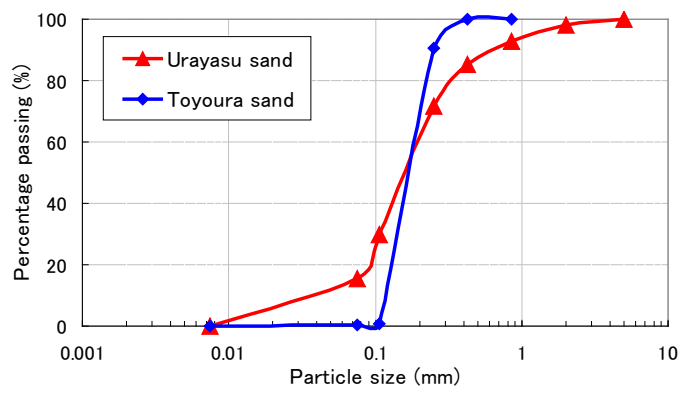

Figure 18: Particle size of sand.

Figures 19 and 20 show the relationships between cyclic shear stress ration and repeated numbers for both sands. In Toyoura sand, the difference of liquefaction intensity in each relative density is seen clearly. On the other hand, liquefaction strength in Urayasu sand is not affected by relative density so much. This result is consistent with the varying fine fraction content's test result by Yokoyama [8]. 
Figure 21 plots the relation of liquefaction strength and relative density of Urayasu sand and Toyoura sand. For a medium sample $(\mathrm{Dr}=60 \%)$, there is no difference, but in a dense sample ( $\mathrm{Dr}=80 \%)$, Urayasu sand has a tendency for smaller liquefaction strength. This tendency can be understood due to the above fine fraction content.

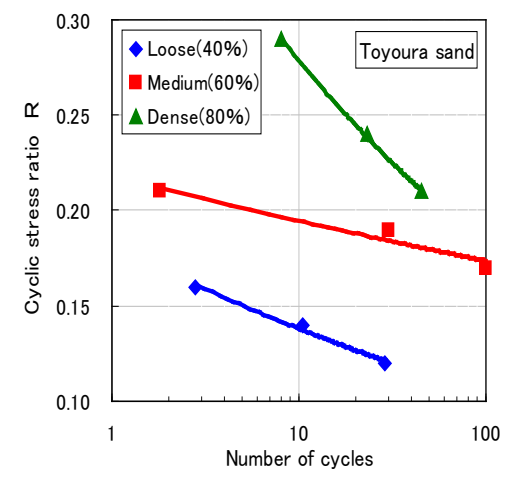

Figure 19: Relationship between cyclic stress ratio and number of cycles (Toyoura sand).

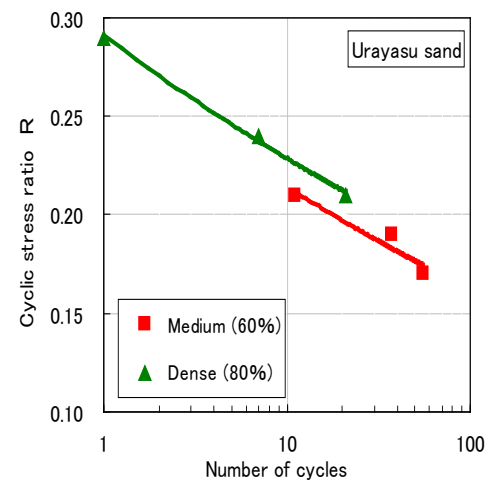

Figure 20: Relationship between cyclic stress ratio and number of cycles (Urayasu sand).

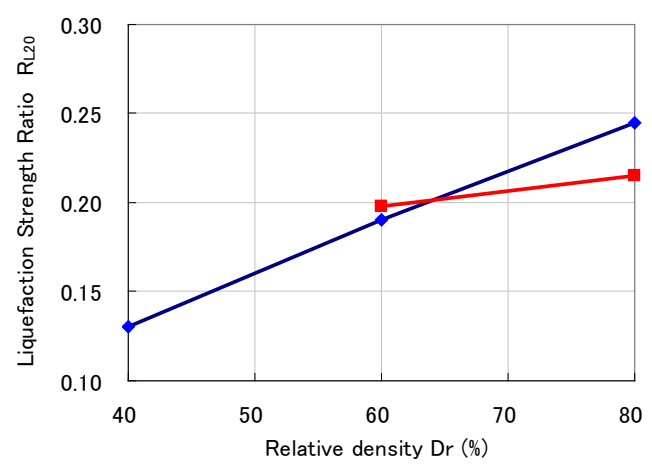

Figure 21: Relationship between liquefaction strength and relative density.

\section{Measures for liquefaction in Urayasu city}

The occurrence of liquefaction needs three conditions.

1) Loose sand deposit,

2) Groundwater, and

3) Earthquake movement.

Therefore, a measure for preventing liquefaction needs to eliminate all three conditions. 
Currently, the principles of liquefaction measures taken in Urayasu is as follows.

- Increase the soil density

- Solidify sand particles

- Lowering the ground water table

- Disperse the pore water pressure

- Control the shear deformation

- Improve the structure

For the selection of construction method with principle improvement, it is influenced largely by size and area requiring improvement. Countermeasures to prevent liquefaction in Urayasu need to apply to many numbers of residential houses, and it is a big characteristic. In other words, the most economical construction method for small size improvement needs to be chosen.

\section{Conclusion}

1) In the Tohoku earthquake, even the Tokyo Bay coast - so far away from the epicentre - suffered a devastating damage caused by soil liquefaction.

2) More than $70 \%$ of the land in Urayasu City, which suffered the largest damage from soil liquefaction, was of landfill sites reclaimed after the 1960s.

3) Calculated FL and PL values by current estimation method indicates a high possibility of liquefaction occurring.

4) The liquefaction resistance test on Urayasu sand revealed that it has smaller resistance to liquefaction despite the fact that it contains fine-grained fractions.

5) Liquefaction resistant structures are mainly used for residential houses, and therefore, choosing an economical and inexpensive resistant structure is of great importance.

\section{References}

[1] Japan Meteorological Agency: http://www.seisvol.kishou.go.jp/eq/ 2011_03_11_tohoku/index.html

[2] Kanto Branch of MLIT and JGS (2011): Report on liquefaction in Kanto District during East Japan Off-Pacific Earthquake (in Japanese).

[3] Nikkei Construction (2011): Mechanism of liquefaction, pp. 40-47, 09 May (in Japanese).

[4] Urayasu city: http://www.city.urayasu.chiba.jp/

[5] Japan Road Association (1996): Bridge Design Specification, Part V Seismic Design.

[6] Iwasaki, T., F. Tatsuoka, K. Tokida, and S. Yasuda (1980): Estimation of degree of soil liquefaction during earthquakes, Soil Mechanics and Foundation Engineering, vol.28, No.4, pp. 23-29 (in Japanese).

[7] Chiba Prefectural Environmental Research Center: http://wwwp.pref. chiba.lg.jp/pbgeogis/servlet/infobank.index

[8] K. Yokoyama (2011): Effect of fine fraction content on liquefaction characteristics, Master thesis of Nihon University (in Japanese). 